\title{
Atuação da Equoterapia na Espondilite Anquilosante ${ }^{(*)}$
}

\section{Activeness of Hippotherapy in Ankylosing Spondilitis}

\section{A EQUOTERAPIA}

A equoterapia é um método terapêutico de reabilitação motora e educacional que busca o desenvolvimento biopsicossocial de pessoas portadoras de deficiência e/ou com necessidades especiais $^{(1,2)}$, reconhecido pelo Conselho Federal de Medicina (Parecer 6/97). A equoterapia tem sido utilizada com êxito em pacientes portadores de síndromes neurológicas ${ }^{(1)}$, sendo citada na literatura para reabilitação de pacientes com instabilidade segmentar lombar ${ }^{(3)}$ e pós-operatório de cirurgia de hérnia discal ${ }^{(4)}$. O passo é a andadura rolada ou marchada, ritmada, a quatro tempos e simétrica em relação ao eixo longitudinal do cavalo, que transmite ao cavaleiro uma série de movimentos seqüenciados e simultâneos, tendo como resultante um movimento tridimensional em ciclos, análogo à marcha do homem ${ }^{(1)}$. Essa foi a razão que nos levou a investigar se a equoterapia poderia ser utilizada como terapêutica auxiliar na espondilite anquilosante. Para tanto, incluímos dois indivíduos portadores de espondilite anquilosante, não praticantes de atividade fisica regular e ou terapia reabilitacional. Os pacientes foram encaminhados por médico reumatologista, e além da terapêutica medicamentosa, foram incluídos em um programa de equoterapia, acompanhados por uma equipe multidisciplinar, composta por fisioterapeuta, psicóloga e instrutor de equitação. $\mathrm{O}$ animal foi conduzido somente ao passo, em seu ritmo natural, guiado pelo condutor sem interferência do paciente. A terapia realizou-se na freqüência de uma sessão semanal, com duração de 30 minutos, em pista oval de 400 metros de perímetro, por um período de nove meses.

Os resultados foram coletados por meio de fichas de avaliação padronizadas, no início do estudo (Avaliação 1), imediatamente após (Avaliação 2) e após quatro meses do término do estudo (Avaliação 3). Os dados objetivos compreenderam as medidas específicas, quais sejam: teste de Schober, distância entre a apófise de C7 à linha das cristas ilíacas, expansibilidade torácica, distância terceiro dedo-chão e distância occipto-parede ${ }^{(5)}$.

Paciente 1 - Paciente do sexo masculino, 24 anos, portador de espondilite anquilosante desde os 18 anos de idade. $\mathrm{Na}$ avaliação 1, referia dores de maior intensidade na região lombar baixa, com irradiação para os quadris e face posterior das coxas, até os joelhos, e dores de menor intensidade, na coluna cervical e nos ombros. Referia dificuldade em executar as atividades da vida diária que exigiam mobilidade na coluna vertebral, como vestir-se e despir-se, calçar meias, amarrar sapatos e escovar os dentes. $\mathrm{Na}$ avaliação 2, efetuada nove meses após a avaliação inicial e início do tratamento em equoterapia, referiu melhora na execução das atividades da vida diária e da sintomatologia dolorosa, permitindo a redução da dose diária de indometacina. Quatro meses após a suspensão da equoterapia, o paciente notou que, quatro semanas após o término da terapia, suas dores e a rigidez na cintura escapular, coluna cervical e lombar aumentaram gradativamente, com diminuição da flexibilidade, flexão e rotação do tronco.

Paciente 2 - Paciente do sexo masculino, 43 anos, portador de espondilite anquilosante desde os 37 anos de idade. $\mathrm{Na}$ avaliação 1, referia dores de maior intensidade na região cervical, e dores de menor intensidade na coluna lombar. $\mathrm{Na}$ pesquisa das atividades funcionais referia dificuldade em calçar meias, em calçar e amarrar sapatos e para higiene após as evacuações. Na avaliação 2, realizada cinco meses após o início do tratamento em equoterapia, referiu melhora na avaliação das atividades funcionais, permitindo a redução da dose de metotrexato de 7,5mg para $5 \mathrm{mg}$ por semana. Quatro meses após a suspensão da terapia, o paciente mantinha-se em uso de $5 \mathrm{mg}$ semanais de metotrexato, referindo dor na região tóraco-lombar, à rotação de tronco e piora da rigidez cervical, com aumento da dificuldade em calçar meias e sapatos.

\footnotetext{
* Trabalho realizado no Departamento de Fisioterapia - Equipe de Equoterapia, da Faculdade de Ciências da Saúde da Universidade do Vale do Paraíba, São José dos Campos, SP, Brasil.

Endereço para correspondência: Milena Nóvoa Assumpção Dias. Rua Dr. Arnaldo de Carvalho, 92, ap. 93, Campo Grande, CEP 11.075-430, Santos, SP, Brasil. Tel. (13) 8124-0542, (13) 3224-9211; e-mail: milenanafisio@hotmail.com
} 
A mensuração de medidas objetivas para os pacientes 1 e 2, antes e após a equoterapia, pode ser visualizada na Tabela 1.

TABELA 1

Mensurações específicas nos Pacientes 1 e 2 , respectivamente

\begin{tabular}{lccc}
\hline Medidas em cm & Avaliação & Avaliação & Avaliação \\
& $\mathbf{1}$ & $\mathbf{2}$ & $\mathbf{3}$ \\
\hline Distância terceiro dedo-chão & $52 / \mathbf{5 0 *}$ & $37,5 / \mathbf{3 7 , 5}$ & $44 / \mathbf{4 4}$ \\
\hline Teste de Schober & $3 / \mathbf{0}$ & $3,5 / \mathbf{3 , 5}$ & 2 / 0,5 \\
Distância C7-crista ilíaca & $2 / 0$ & $3,5 / \mathbf{3 , 5}$ & $3 / \mathbf{0 , 5}$ \\
\hline Distância occipto-parede & $0 / \mathbf{1 3}$ & $0 / \mathbf{1 1}$ & $6 / \mathbf{1 4 , 5}$ \\
Expansibilidade torácica & $1,5 / \mathbf{1 , 5}$ & $1,5 / \mathbf{3}$ & $1,5 / \mathbf{2}$ \\
\hline
\end{tabular}

${ }^{*}$ Algarismos em negrito $=$ paciente 2

Existem poucos trabalhos científicos na literatura mundial sobre os recursos terapêuticos da equoterapia. Na presente amostra, embora os pacientes relatados fossem de faixas etárias distintas e de diferentes estágios evolutivos da doença, com a prática da equoterapia ambos os pacientes apresen-

\section{REFERÊNCIAS}

1. Medeiros M, Dias E: Equoterapia; Bases e fundamentos, Rio de Janeiro, Revinter, 2002

2. Ande-Brasil. Disponível em: http://www.equoterapia.org.br/ equoterapia.html.

3. Rothhaupt D, Ziegler H, Laser T: Orthopedic hippotherapy - new methods in treatment of segmental instabilities of the lumbar spine. Wien Med Wochenschr 147: 504-8, 1997. taram melhora das queixas subjetivas, das atividades da vida diária e dos parâmetros objetivos avaliados. Não foram observadas alterações que causassem a piora do quadro clínico dos pacientes ou que lhe provocassem efeitos maléficos, durante a prática da equoterapia. Deste modo, a equoterapia mostrou-se como mais um recurso disponível na terapêutica da espondilite anquilosante, com resultados satisfatórios. Apesar da pequena amostragem de pacientes, nossos dados preliminares sugerem, de maneira inédita, que esta modalidade terapêutica pode auxiliar no tratamento da espondilite anquilosante.

Agradecimentos: a Professora Regiane Albertini de Carvalho e a Marcelo Eduardo Osses.

Milena Nóvoa Assumpção Dias Fisioterapeuta, especialista em equoterapia

Carlos Eduardo Araújo Fortes Fisioterapeuta, especialista em equoterapia e ortopedia

Renato Pereira Dias Médico reumatologista, especialista em equoterapia

4. Rothhaupt D, Laser T, Ziegler H, Liebig K: Orthopedic hippotherapy in postoperative rehabilitation of lumbar intervertebral disk patients. A prospective, randomized therapy study. Sportverletz Sportschaden 11: 63-9, 1997.

5. Pile KD, Laurent MR, Salmond CE et al: Clinical assesment of ankylosing spondylitis: a study of observer variation in spinal measurements. Br J Rheumatol 30: 29, 1991. abe-se que os residentes são cobrados, por seus preceptores, a publicar. O resultado é óbvio: enriquecem seus currículos, somam pontos para a prova de título de especialista em reumatologia, enfim, iniciam-se na pesquisa médica. Por outro lado, os preceptores também são estimulados pela universidade, pelo colegiado de pós-graduação e pelo próprio serviço a que pertencem, a publicar... Une-se, então, o útil ao agradável, e com uma só cajadada matam-se os coelhos.

Entretanto, não se deve esquecer da qualidade do trabalho a ser encaminhado para a Revista Brasileira de Reumatologia. Os novos pesquisadores não poderiam ou não deveriam ter seu trabalho rejeitado, é desanimador, é desalentador. Não devem e nem podem esmorecer. Cabe, então, aos precep- tores cobrar, ensinar e, principalmente, "sentar-se" com o jovem médico e avaliar bem o artigo a ser enviado para publicação. Temos observado, ao longo dos anos, que a Revista Brasileira de Reumatologia tem recebido artigos em que faltam: revisão do português (nossa língua pátria); cronologia entre tratamentos de pacientes, seus efeitos terapêuticos e os para-efeitos; conclusões precipitadas e sem respaldo, dentre outros.

Lembre-se: a Revista Brasileira de Reumatologia é a mais importante publicação na área da reumatologia da América Latina e, mais importante ainda, é a nossa revista!

Marco Antonio P. Carvalho Professor, doutor da Faculdade de Medicina da UFMG 